\title{
ERECTILE DYSFUNCTION IN HAEMODIALYSIS PATIENTS- A CROSS-SECTIONAL STUDY AT VAATSALYA HOSPITAL, SHIMOGA, INDIA
}

\author{
Girish I1, Malvade Praveen ${ }^{2}$
}

${ }^{1}$ Consultant Physician, Department of General Medicine, Vaatsalya Hospital, Shimoga, Karnataka.

${ }^{2}$ Consultant Nephrologist, Department of General Medicine, Vaatsalya Hospital, Shimoga, Karnataka.

\section{BACKGROUND}

ABSTRACT

With the advancement in the medical treatment and haemodialysis techniques, life expectancy of ESRD patients has increased significantly, and this fact has highlighted the importance of quality of life of HD patients. Sexual dysfunction is most commonly seen in patients with ESRD on maintenance haemodialysis in the form of erectile dysfunction, decreased libido and decreased frequency of sexual intercourse.

The proposal of this study was to determine the prevalence of erectile dysfunction (ED) among haemodialysis (HD) patients.

\section{MATERIALS AND METHODS}

A cross-sectional study was conducted to determine the prevalence of ED among a community-based haemodialysis (HD) population at Vaatsalya Hospital, Shimoga. The presence and severity of ED were assessed among 50 ESRD patients using the selfadministered International Index of Erectile Function-5 (IIEF-5). Clinical, demographic and laboratory data of all patients were collected from June 2017 to November 2017.

\section{RESULTS}

60 patients on MHD were assessed. 5 were excluded due to cognitive dysfunction. 3 did not consent. 2 had problems with communication. 50 patients were included in the final cohort. Nearly, all were hypertensive (94\%) and 58\% had diabetes. The cause of ESRD was Diabetes (58\%), Hypertension (6\%), Nephritis (20\%) and others (16\%). The prevalence of ED was $82 \%$ (CI, 76 to $87 \%$ ) for all HD subjects. Majority of the patients had mild-to-moderate dysfunction (48\%) and about $34 \%$ of patients had severe erectile dysfunction.

\section{CONCLUSION}

ED is extremely prevalent among HD patients. Early intervention may change quality of life of these patients.

\section{KEYWORDS}

Erectile Dysfunction, ESRD, Haemodialysis, Diabetes Mellitus.

HOW TO CITE THIS ARTICLE: Girish I, Praveen M. Erectile dysfunction in haemodialysis patients- a cross-sectional study at Vaatsalya hospital, Shimoga, India. J. Evolution Med. Dent. Sci. 2018;7(04):471-473, DOI: 10.14260/jemds/2018/105

\section{BACKGROUND}

With the advancement in the medical treatment and haemodialysis techniques, life expectancy of ESRD patients has increased significantly, and this fact has highlighted the importance of quality of life of HD patients. ${ }^{1}$

Sexual dysfunction is most commonly seen in patients with ESRD on maintenance haemodialysis in the form of erectile dysfunction, decreased libido and decreased frequency of sexual intercourse. ${ }^{2-3}$ Many studies in men with ESRD have shown that prevalence of ED in men with ESRD on HD may range from $41.5 \%$ to $82 \%$ and is directly associated with severity of the illness. ${ }^{4-8}$ Erectile dysfunction (ED) is a medical problem that alters patient's quality of life due to association with many problems such as anxiety, loss of selfesteem, depression and marital misfit. ${ }^{9}$ ED is defined as the

'Financial or Other Competing Interest': None.

Submission 27-12-2017, Peer Review 10-01-2018,

Acceptance 13-01-2018, Published 22-01-2018.

Corresponding Author:

Dr. Malvade Praveen,

Consultant Nephrologist,

Vaatsalya Hospital, Park Extension,

Opposite to Malnad Diagnostics,

Shimoga-577201.

E-mail: malvadepraveen3@gmail.com

DOI: $10.14260 /$ jemds $/ 2018 / 105$ inability to attain and sustain an erection sufficient to achieve a satisfactory sexual intercourse. There are many reasons to expect a high prevalence of ED in HD populations.

A number of illnesses such as atherosclerosis, heart disease, diabetes and hypertension that are associated with ED also tend to be common among patients with ESRD. Medications frequently used in the setting of renal disease have also been associated with ED including several diuretics, anti-hypertensives, antidepressants and $\mathrm{H} 2$ antagonists. In this study, we aimed to determine the prevalence of ED among HD patients.

\section{MATERIALS AND METHODS}

A cross-sectional study on 50 patients with ESRD on maintenance haemodialysis in dialysis unit of Vaatsalya Hospital, Shimoga during June to November 2017 using the International Index Erection Function (IIEF).

\section{Inclusion Criteria}

- Patients with ESRD on maintenance HD at three times a week.

- $\quad$ Male sex.

- Patients who gave consent and provided complete history for ED.

- $\quad$ Age $>18$ years.

- On MHD for at least 3 months. 


\section{Exclusion Criteria}

- Patients with acute kidney injury, on haemodialysis.

- Female sex.

- Patients who did not give consent.

- Had cognitive or communication impairment.

\section{Data Collection/ Comorbidity and Functional Status}

Medical and demographic data were obtained for each subject from abstraction of dialysis records. Medical data collected included measures of health status, duration of dialysis, comorbid conditions, laboratory studies such as haemoglobin, creatinine, albumin and parathyroid hormone, adequacy of dialysis, compliance with dialysis, prior transplantation and current medications.

\section{Sexual Function}

The questions of EF domain from IIEF 5 were self-answered by each patient during HD sessions.

\section{The IIEF-5 Score is the Sum of the Ordinal Responses to the 5 items}

- 22-25: No erectile dysfunction

- 17-21: Mild erectile dysfunction

- 12-16: Mild-to-moderate erectile dysfunction

- 8-11: Moderate erectile dysfunction

- 5-7: Severe erectile dysfunction

\section{Statistical Analysis}

Descriptive statistics was used to calculate the frequency, mean and standard deviation. Microsoft Word and Excel have been used to generate the tables and figures.

\section{RESULTS}

This study included 50 male patients of ESRD who were on maintenance HD and who were able to perform intercourse. Prevalence of ED was $82 \%(n=41)$ with mean IIEF-5 was $12.44 \pm 7.264$.

\begin{tabular}{|c|c|c|}
\hline Causes of ESRD & $\mathbf{n}$ & $\mathbf{\%}$ \\
\hline Diabetes & 29 & 58 \\
\hline Hypertension & 3 & 6 \\
\hline Nephritis & 10 & 20 \\
\hline Others & 8 & 16 \\
\hline \multicolumn{2}{|c|}{ Table 1. Causes of ESRD } \\
\hline
\end{tabular}

Major cause of ESRD was Diabetes Mellitus 58\% ( $n=29)$ and Hypertension $6 \%(n=3)$, nephritis $20 \%(n=10)$, cystic disease $4 \%(n=2)$ and other $12 \%(n=6)$. Mean duration of the dialysis was $19 \pm 72$ months. $16 \%$ of patients were on maintenance HD for 6 months to 1 year, $24 \%$ for 1 to 2 years, $35 \%$ for 2 to 4 years and $25 \%$ for more than four years.

\begin{tabular}{|c|c|c|}
\hline Frequency of Dialysis & n & \% \\
\hline Once a week & 12 & 24 \\
\hline Twice a week & 18 & 36 \\
\hline Thrice a week & 20 & 40 \\
\hline \multicolumn{2}{|c|}{ Table 2. Frequency of Dialysis } \\
\hline
\end{tabular}

$40 \%$ of the patients had thrice a week dialysis, $35 \%$ percent patients were getting twice weekly dialysis and $24 \%$ of patients had only once a week dialysis.

\begin{tabular}{|c|c|c|c|}
\hline Status & & $\mathbf{N}$ & $\mathbf{\%}$ \\
\hline \multirow{2}{*}{ HBsAg } & Positive & 2 & 4 \\
\cline { 2 - 4 } & Negative & 48 & 96 \\
\hline \multirow{2}{*}{ HCV } & Positive & 1 & 2 \\
\cline { 2 - 4 } & Negative & 49 & 98 \\
\hline \multicolumn{2}{|c|}{ Table 3. HBsAg and HCV Status } \\
\hline
\end{tabular}

Majority of the patients were HBsAg and anti-HCV negative.

\begin{tabular}{|c|c|c|}
\hline $\begin{array}{c}\text { Erectile } \\
\text { Dysfunction }\end{array}$ & $\mathbf{n}$ & $\mathbf{\%}$ \\
\hline Mild & 14 & 28 \\
\hline Moderate & 10 & 20 \\
\hline Severe & 17 & 34 \\
\hline \multicolumn{2}{|c|}{ Table 4. Severity of ED } \\
\hline
\end{tabular}

About 34\% ( $\mathrm{n}=17)$ had severe ED and majority of patients $48 \%(n=24)$ had mild-to-moderate degree of ED. Only $18 \%$ of patients were normal.

\section{DISCUSSION}

ED is a common problem in male patients with chronic kidney disease undergoing haemodialysis, and many studies have shown that there is high prevalence of ED in men with ESRD undergoing maintenance dialysis. ${ }^{10}$ In our study, prevalence of erectile dysfunction was $82 \%$ among prevalent haemodialysis patients. Finding was consistent with prior published research. Majority of the patients had mild-tomoderate dysfunction (48\%) and about $34 \%$ of patients had severe erectile dysfunction.

Abram and collaborators in 1975 showed that the prevalence of ED in HD patients was around $80 \% \cdot{ }^{11}$ Another study done in 1981 showed a prevalence of erectile dysfunction in patients undergoing haemodialysis was $50 \%$. Rodger, Fletcher and Devar et al studied 100 patients with CKD on maintenance haemodialysis and found ED in 61\% of patients. ${ }^{12}$ Similar prevalence of ED was observed in studies done in Iran (87.5\%), ${ }^{13}$ Turkey (82.9\%), ${ }^{14}$ Egypt (82.5\%) and Brazil (86.4\%). ${ }^{15}$

Causes of erectile dysfunction in patients on HD is multifactorial which includes metabolic causes, disruption of the HPA axis, ${ }^{16-17}$ alteration in plasma levels of gonadotropins, testosterone, prolactin ${ }^{18}$ and zinc, ${ }^{19-20}$ medications like beta-blockers and antidepressants are responsible for ED. 21

Patients who underwent regular dialysis had less incidence of ED. ${ }^{22}$ In our study, patients who were underdialysed had higher prevalence of ED.

In our study, mean duration of the dialysis was 19 months and duration of the dialysis did not have statistically significant effect on ED. Similarly, Steele et $\mathrm{al}^{23}$ in his study showed that there was no association between duration of dialysis and start of ED.

Patients with diabetes and CKD had greater prevalence of sexual dysfunction due to the arterial pathology. ${ }^{24}$ In this study group, $99 \%$ of the diabetic patients displayed ED complaints.

In our study, cardiovascular disease was found to be associated with ED. Similarly, many studies have proved an association of ED and cardiovascular. ${ }^{25}$

Despite having performed a population-based sampling of male patients on HD, our study has several limitations, because the sample size was small and presence of ED and 
associated conditions and exposures were assessed simultaneously. It was impossible to determine whether we identified causal associations with ED. All of our measures of ED were based on self-reporting, and no other physical or diagnostic tests were done. We have made an attempt to standardise self-report of ED by using a questionnaire that has been validated in other settings. ${ }^{26-28}$

\section{CONCLUSION}

Erectile dysfunction is highly prevalent in male patients undergoing maintenance HD. Quality of life in patients with ED is poor. Early diagnosis and prompt treatment of sexual dysfunction will help to improve the quality of life in ESRD patients on HD.

\section{ACKNOWLEDGEMENTS}

Authors acknowledge the immense co-operation received by the patients and the help received from the scholars whose articles are included and cited in references of this manuscript. The authors are also grateful to authors/ editors/ publishers of all those articles, journals and books from where the literature for this article has been reviewed and discussed.

\section{REFERENCES}

[1] Rosas SE, Joffe M, Franklin E, et al. Association of decreased quality of life and erectile dysfunction in hemodialysis patients. Kidney Int 2003;64(1):232-8.

[2] Palmer BF. Sexual dysfunction in men and women with chronic kidney disease and end-stage kidney disease. Adv Ren Replace Ther 2003;10(1):48-60.

[3] Diemont WL, Vruggink PA, Meuleman EJ, et al. Sexual dysfunction after renal replacement therapy. Am J Kidney Dis 2000;35(5):845-51.

[4] Sherman FP. Impotence in patients with chronic renal failure on dialysis: its frequency and etiology. Fertil Steril 1975;26(3):221-3.

[5] Procci WR, Goldstein DA, Adelstein J, et al. Sexual dysfunction in the male patient with uremia: a reappraisal. Kidney Int 1981;19(2):317-23.

[6] Breza J, Reznicek J, Pribylincova V, et al. Erectile dysfunctions in patients treated with hemodialysis and kidney transplantation. Bratisl Lek Listy 1993;94(9):489-93.

[7] Palmer BF. Sexual dysfunction in uremia. J Am Soc Nephrol 1999;10(6):1381-8.

[8] Rosas SE, Joffe M, Franklin E, et al. Prevalence and determinants of erectile dysfunction in hemodialysis patients. Kidney Int 2001;59(6):2259-66.

[9] Makhlouf A, Kparker A, Niederberger CS. Depression and erectile dysfunction. Urol Clin North Am 2007;34(4):565-74, vii.

[10] Ali ME, Abdel-Hafez HZ, Mahran AM, et al. Erectile dysfunction in chronic renal failure patients undergoing hemodialysis in Egypt. Int J Impot Res 2005;17(2):180-5.

[11] Abram HS, Hester LR, Sheridan WF, et al. Sexual functioning in patients with chronic renal failure. J Nerv Ment Dis 1975;160(3):220-6.

[12] Rodger RS, Fletcher K, Dewar JH, et al. Prevalence and pathogenesis of impotence in one hundred uremic men. Uremia Invest 1984-1985;8(2):89-96.
[13] Mehrsai S, Mousai M, Xthoobonkt $\mathrm{T}$, et al. Improvement of erectile dysfunction KTP. Urology Journal 2006;3(4):240-3.

[14] Inci K, Hazirolan T, Ati FT, et al. Coronary artery calcification in HD patients and their correlation with the prevalence of ED. Transplant Proc 2008;40(1):7780.

[15] Neto AF, de Freitas Rodrigues MA, Saraiva Fittipaldi JA, et al. The epidemiology of ED and its correlation in men with chronic renal failure on hemodialysis in Londrina, Southern Brazil. Int J Impot Res 2002;14(Suppl 2):S19-26.

[16] Holdsworth SR, de Kretser DM, Atkins RC. A comparison of hemodialysis and transplantation in reversing the uremic disturbance of male reproductive function. Clin Nephrol 1978;10(4):146-50.

[17] Chopp RT, Mendez R. Sexual function and hormonal abnormalities in uremic men on chronic dialysis and after renal transplantation. Fertil Steril 1978;29(6):661-6.

[18] Bommer J, Ritz E, del Pozo E, et al. Improved sexual function in male haemodialysis patients on bromocriptine. Lancet 1979;2(8141):496-7.

[19] Mahajan SK, Abbasi AA, Prasad AS, et al. Effect of oral zinc therapy on gonadal function in hemodialysis patients. A double with blind study. Ann Intern Med 1982;97(3):357-61.

[20] Antoniou LD, Shalhoub RJ, Sudhakar T, et al. Reversal of uraemic impotence by zinc. Lancet 1977;2(8044):895-8.

[21] Bao J, Yu Q, Yu H, et al. Erectile dysfunction in male hemodialysis patients in China-one centre experience. Clin Nephrol 2011;75(2):135-40.

[22] Malekmakan L, Shakeri S, Haghpanah S, et al. Epidemiology of erectile dysfunction in hemodialysis patients using IIEF questionnaire. Saudi J Kidney Dis Transpl 2011;22(2):232-6.

[23] Steele TE, Wuerth D, Finkelstein S, et al. Sexual experience of the chronic peritoneal dialysis patient. J Am Soc Nephrol 1996;7(8):1165-8.

[24] Kaufman JM, Hatzichristou DG, Mulhall JP, et al. Impotence and chronic renal failure: a study of the hemodynamic pathophysiology. J Urol 1994;151(3):612-8.

[25] Wabrek AJ, Burchell RC. Male sexual dysfunction associated with coronary heart disease. Arch Sex Behav 1980;9(1):69-75.

[26] Rosen RC, Cappelleri JC, Smith MD, et al. Development and evaluation of an abridged, 5-item, version of the IIEF as a diagnostic tool for erectile dysfunction. Int J Impot Res 1999;11(6):319-26.

[27] Rosen RC, Riley A, Wagner G, et al. The international index of erectile function (IIEF): a multidimensional scale for assessment of erectile dysfunction. Urology 1997;49(6):822-30.

[28] Goldstein I, Lue TF, Padma-Nathan $\mathrm{H}$, et al. Oral sildenafil in the treatment of erectile dysfunction. $\mathrm{N}$ Engl J Med 1998;338(20):1397-404. 